\title{
Aspectos Cognitivos da Memória e a Antecipação da Prova Testemunhal no Processo Penal
}

\author{
Rafael Altoé* \\ Gustavo Noronha de Avila**
}

1 Introdução. 2 Aspectos cognitivos da memória. 3 Prova testemunhal e a memória declarativa episódica: aspectos da sugestionabilidade e a urgência presumida na colheita da prova. 4 É preciso antecipar a prova testemunhal: uma análise a partir da Súmula 455 do STJ. 5 Conclusão. Referências.

\section{RESUMO}

A prova testemunhal é baseada, essencialmente, na ideia de que o ser humano, por meio da memória declarativa episódica (uma espécie de um amplo gênero), tem a especial capacidade de reproduzir, com bastante fidelidade, um evento passado. Ocorre, porém, que as recentes descobertas no campo da psicologia do testemunho atestam que a memória, em verdade, tem se apresentado como um fenômeno mais complexo do que popularmente se acredita. As múltiplas etapas da formação da memória (em especial a codificação, o armazenamento e a evocação) ocorrem por força da atividade simultânea de variadas regiões do cérebro, com influência de aspectos endógenos e exógenos. Por causa dessa afirmação, acredita-se que a memória não é o "resgate" de uma informação previamente armazenada, mas legítimo processo de construção. Essa complexidade, como não poderia ser diferente, vem acompanhada de riscos acerca da confiabilidade da memória, cujos dados o Processo Penal não pode ignorar. Ressalta-se, apenas como um dos elementos possíveis, que o tempo pode ter influência na confiabilidade da memória de maneira mais contundente do que se acredita, de maneira que a antecipação da prova testemunhal, sempre que possível, deve ser levada a efeito em nome da melhor solução do caso objeto do processo judicial.

Palavras-chave: Processo Penal. Memória. Falibilidade. Prova testemunhal. Antecipação.

Mestre em Ciência Jurídica do Centro de Ensino Superior de Maringá (Unicesumar). Professor da Escola da Magistratura do Paraná (EMAP). Juiz de Direito no Estado do Paraná. E-mail: < rafaelaltoe@ hotmail.com>.

** Doutor e Mestre em Ciências Criminais pela Pontifícia Universidade Católica do Rio Grande do Sul (PUCRS). Professor do Mestrado em Ciência Jurídica do Centro de Ensino Superior de Maringá (Unicesumar). Professor do Departamento de Direito Público da Universidade Estadual de Maringá (UEM). E-mail: < gustavonoronhadeavila@gmail.com>. 


\section{INTRODUÇÃO}

O Processo Penal brasileiro, fruto de uma crença na especial capacidade retrospectiva da mente humana, é estruturado na ideia do resgate de fatos pretéritos. Com base nessas características, compartilhando da lógica formal de outros ramos, o sistema processual brasileiro tem na confiança na memória da testemunha seu principal ponto de legitimidade.

Ao buscar a apuração de fatos imputados a determinada pessoa, todo o procedimento processual acaba por exigir, ainda que em múltiplas variáveis, a valoração da prova testemunhal para decisão do caso, buscando sempre apurar um conjunto de informações transmitidas por pessoas que, por aspectos sensoriais, tiveram contato com o episódio denunciado. Pessoas que viram, ouviram, ou experimentaram outra forma de contato sensorial com o fato apurado passam a ser compelidas a promover, com maior fidelidade possível, a reconstrução do evento a que tiveram contato.

Ocorre, porém, que, ao mesmo tempo em que atribui à prova testemunhal o peso de ser determinante para os possíveis destinos do processo, pouco contribui, de forma legítima, para a conservação da confiabilidade desse tipo de prova. As supostas medidas elegidas pelo legislador com o objetivo de conservar a prova oral possuem pouca aplicabilidade, notadamente ante a falta de maior delimitação sobre qual é, verdadeiramente, a segurança da memória humana e qual é o risco que o tempo opera na modificação ou eliminação dessas informações.

Pesquisas recentes têm indicado, além disso, que não é apenas a dificuldade de preservação da memória que merece maior reflexão. Em verdade, a própria veracidade do conteúdo recordado é, nos dias atuais, objeto de grandes questionamentos. Destacam-se, neste ponto, as falsas memórias, ${ }^{1}$ consistentes em recordações inverídicas não intencionais (desprovidas de qualquer reflexo de má-fé) que surgem nas pessoas por diversos fatores. ${ }^{23}$

Acrescente-se, ainda, a constatação científica de que a memória é sugestionável em variados graus, podendo ser moldada ou criada em determinadas circunstâncias. A forma de se questionar uma testemunha, o ambiente a que está submetida, situações endógenas e exógenas de múltiplos aspectos, são apenas algumas das situações que podem ser indicadas para atestar que é possível, inclusive, fazer surgir a recordação de um evento que nunca existiu ou que ocorreu de forma diversa da rememorada.

Com base nesses apontamentos, questiona-se: a forma com que o processo penal brasileiro tem tratado a prova testemunhal ignora os riscos apontados? A preservação da prova testemunhal é considerada, de forma suficiente, no Processo Penal?

No objetivo de responder a esses questionamentos, foram elaborados três capítulos e, ao final, apresentada a conclusão extraída.

Além disso, vale mencionar que a pesquisa se amparou no método teórico, sem prejuízo de serem citados experimentos extraídos das obras utilizadas no curso da pesquisa. 
No primeiro capítulo, são abordados alguns aspectos cognitivos da memória humana (pouco, dada a complexidade do assunto), buscando situar as premissas de que a memória não é puramente biológica e, por tal razão, manifesta-se como um fenômeno complexo de construção, que é passível de múltiplas influências.

Já no segundo capítulo, ingressa-se na análise da memória declarativa episódica, espécie que dá base à prova testemunhal (embora existam outras espécies a serem consideradas em outros estudos). São identificadas algumas características dessa espécie de memória, sobretudo sua maior plasticidade, que permitem uma particular influência da sugestionabilidade. Também se avaliam os possíveis riscos que o tempo pode operar nesse tipo de memória.

No terceiro e último capítulo, promove-se a valoração acerca da possibilidade ou não de antecipação da prova testemunhal no Processo Penal, apenas por conta do decurso do tempo. Em especial, enfoca-se a questão se o decurso do tempo é motivo bastante para produção antecipada da prova na hipótese de suspensão do processo na forma do artigo 366 do Código de Processo Penal. Para tanto, realiza-se o cotejo das contribuições recentes da psicologia do testemunho, com as razões que embasam a Súmula 455 do Superior Tribunal de Justiça.

\section{ASPECTOS COGNITIVOS DA MEMÓRIA}

A memória é um fenômeno profundamente complexo e que, por força de suas intrigantes características, sequer foi compreendido plenamente nos dias atuais. Embora algumas pessoas tendam a conceituar a memória de forma ampla, tratando-a, por exemplo, como "a capacidade de repetir um desempenho" 4 , o fato é que o próprio conceito de memória, como melhor se verá adiante, é bastante indefinido.

De tempos em tempos, novas pesquisas surgem sobre o tema, e, embora consigam desvendar, em parcial medida, alguns fragmentos dos mistérios que a memória carrega, apenas comprovam que ainda há longo caminho a ser trilhado para compreender, de forma segura, o assunto. Conforme afirma Gustavo Noronha de Ávila, “a memória pode ser vista como um fenômeno biológico, fundamental e extremamente complexo, e continua a ser um dos grandes enigmas da natureza." ${ }^{5}$

Em um primeiro momento, a memória foi entendida apenas como uma manifestação corporal, fruto dos sistemas biológicos, e que estaria imune às interferências que sejam alheias à biologia. ${ }^{6}$ Esse comportamento fez com que inúmeros pesquisadores passassem a buscar, muitas vezes de maneira incansável, um lugar dentro do cérebro humano em que a memória poderia estar armazenada.

Partia-se da premissa de que as incontáveis funcionalidades do sistema cerebral humano seriam autônomas, de modo que cada região do sistema nervoso teria uma função própria e autossuficiente. Rechaçava-se, como consequência, a ideia contemporânea de que, na 
realidade, a atividade cerebral humana é revestida de profunda complexidade, havendo em cada manifestação da pessoa a atuação conjunta das várias regiões do cérebro. Essa forma de pensar justificou a mencionada propensão que alguns cientistas adotaram em buscar o espaço ou o local em que a memória poderia ser guardada.

Enfim, tal qual ocorre com o estudo sobre qual a região do cérebro humano é a responsável pelos controles motores do corpo, acreditava-se que a memória, como fenômeno puramente biológico, poderia ser localizada dentro de uma região particular do cérebro humano. Nessa busca, alguns experimentos foram realizados com a pretensão de descobrir ou acessar o misterioso local do cérebro em que a memória poderia estar "armazenada".

Embora atualmente não se conceba mais a ideia de que a memória possa ser acessada em um local específico - sendo, como mais adiante se verá, um processo de construção que conta com atuação simultânea de diversas áreas -, os experimentos científicos mencionados puderam, ao menos, identificar que o hipocampo é uma região do cérebro essencial para o processo da memória. Em alguns experimentos, foi possível observar que o hipocampo exerce papel importante no misterioso processo da memória, embora não seja suficiente para compreendê-lo.

Atualmente, inclusive contando com as valiosas contribuições dos mencionados experimentos, reconhece-se que a memória, na verdade, sequer pode ser encarada como uma informação específica armazenada dentro da mente humana. Poucas dúvidas há no sentido de que inúmeros fatores, endógenos e exógenos, inter-relacionam-se para a construção da memória, ressaltando-se a complexidade do tema. A emoção, o ambiente externo, a capacidade de atenção, o cansaço, dentre outros aspectos, são alguns fatores que promovem atuação conjunta para a memória.

Sobre o tema, aprofundada a ideia de influência de fatores associados, vale consignar as lições de Iván Antonio Izquierdo, Jociane de Carvalho Myskiw, Fernando Benetti e Cristiane Regina Guerino Furini:

Todas as memórias são associativas: se adquirem através da ligação entre um grupo de estímulos (um livro, uma sala de aula) e outro grupo de estímulos (o material lido, aquilo que se aprende; algo que causa prazer ou penúria). $\mathrm{O}$ do segundo grupo, que é de maiores consequências biológicas, chama-se estímulo condicionado ou reforço. Em algumas formas de aprendizado, associa-se um grupo de estímulos com a ausência do outro ou de qualquer outro. ${ }^{7}$

Como consequência dessa combinação, é possível afirmar, com razoável tranquilidade, que a memória não é "resgatada" na mente humana. Em verdade, como se verá no tópico seguinte, quando determinada pessoa tenta promover o "acesso" à memória, reconstituindo mentalmente um fato passado, na verdade acaba por desencadear um processo de "construção" de uma imagem mental. Aludido processo, conforme inúmeros estudos específicos, é passível de influências e falhas que permitem, em última análise, a criação, por exemplo, de falsas memórias. ${ }^{8}$ 
Alan Baddeley, Michael C. Anderson e Michael W. Eysenkc ${ }^{9}$ citam que uma das maiores provas da complexidade da memória reside na capacidade de esquecimento, o que se traduz em um mecanismo essencial para a vida em alguns aspectos. De maneira ainda não elucidada, mas certo que de forma inata (alheia aos controles racionais), o ser humano tem a aptidão natural de bloquear determinados eventos traumáticos em certas ocasiões, permitindo que sejam acessados apenas em raras oportunidades, ou por vezes sejam completamente bloqueados.

Ainda, olvidar os detalhes dos múltiplos episódios diários é, acima de tudo, medida essencial para que seja possível, mesmo que figurativamente, um dia novo. Sem confundir esse aspecto com a popular visão da "falha da memória" (relacionada ao esquecimento de dados ou atividades importantes), todo ser humano, sem qualquer risco de exceção, só consegue realizar novas atividades e adquirir novos conhecimentos a partir de um proporcional instrumento de esquecimento. ${ }^{10} \mathrm{E}$ isso é feito de maneira automática, sem que a pessoa tenha o domínio desses cursos mentais. Nesse particular, é incontestável a conclusão de que ninguém consegue se recordar de todos os detalhes de uma imagem vivenciada, e essa abordagem não se reduz apenas às mais tímidas informações ou às filigranas desimportantes.

Tenha-se de forma imaginária, em caráter ilustrativo, como seria a vida de uma pessoa que se recordasse de todos os detalhes, sem qualquer esquecimento, do que vivenciou. Cada processo de evocação da memória seria extremamente duradouro, temporalmente idêntico ao episódio vivenciado, o que impediria que o ser humano se imergisse em novas experiências.

Essas breves considerações indicam um ponto relevante para todo debate relativo à memória episódica (aquela que busca refletir um fato passado que pela pessoa foi experimentado): nessa forma especial de memória - que é o objeto da prova testemunhal - jamais será possível cogitar de uma retratação perfeita do episódio da vida que se tenta resgatar. Em outras palavras, a memória declarativa episódica trabalha a partir de fragmentos do que ocorreu, e a compreensão desse importante ponto tem utilidade até mesmo para se ter de critério quando determinado testemunho é ou não verdadeiramente confiável.

Diferentemente do que muito se alega no campo jurídico - destacando-se aqueles que defendem que o estudo da memória seria matéria desimportante para o processo, ou que seria discurso dolosamente criado para obstar qualquer resquício de confiança na testemunha - $\mathrm{O}$ fato é que a investigação sobre as manifestações da memória tem, por afirmações empíricas, incontestável importância. Serve, como exemplo, para dar melhores parâmetros para a produção da prova testemunhal com mais qualidade, e ainda garantir maior conhecimento para que se possa identificar, com mais precisão, quando determinado testemunho é ou não confiável. Além disso, permite o desenvolvimento de técnicas de oitiva que possibilitem que a testemunha entregue a informação com maior propriedade, e de maneira menos constrangedora, o que interessa à decisão judicial pela confiança proporcionada na prova, garantindo maior confiança ao próprio sistema processual. 
Seriam inúmeros os exemplos que podem ser indicados a respeito da essencialidade que reside em melhor entender a complexidade da memória (sobretudo a memória declarativa episódica). Ilustre-se, por exemplo, que uma excessiva riqueza de detalhes em determinado relato, trazendo informações e minúcias ordinariamente não localizadas na generalidade dos testemunhos, pode indicar, desde que aliados a outros elementos, a ausência de veracidade do testemunho (o que não significa necessariamente má-fé, ante a já mencionada existência dos riscos das falsas memórias).

Gustavo Noronha de Ávila e Alexandre Morais da Rosa, valendo-se de interessante figura de linguagem, apontam que a memória é como o diamante (quanto mais falsa, mais perfeita). ${ }^{11}$ Quanto mais "perfeito" for o relato, o que se entende por uma narrativa impassível de olvidar detalhes, muitas vezes, desimportantes, ou excessivamente perfeita mesmo depois do decurso do tempo, há um indicativo de que possivelmente se está diante de um falso. Esses dados, como se nota, são essenciais para todos que atuam no Processo Penal, independentemente do referencial teórico de cada um.

Elizabeth Loftus, um dos principais nomes das pesquisas sobre falsas memórias, definiu, após sucessivos experimentos, que a memória não deve ser pensada como um registro fotográfico ou como um vídeo gravado por uma câmera. ${ }^{1213}$

Diferentemente do que popularmente se imagina (que se é capaz de reproduzir um fato passado pela imagem mental do filme armazenado), o resultado da informação proveniente do processo de (re)construção da memória nasce, na verdade, de ao menos três etapas sucessivas que não estão imunes a múltiplas influências: a codificação, o armazenamento (de curta e longa duração) e a evocação. Aliam-se a essas três etapas os incontáveis fatores determinantes para a qualidade e para a quantidade de informações que, uma vez somadas, transmitirão um esboço de resultado que jamais terá o condão de reproduzir, com exatidão perfeita, o fato da vida passado.

A codificação, como primeira etapa da formação da memória, dá-se na forma pela qual o ser humano faz com que a informação obtida seja assimilada e possa ingressar no segundo estágio. Após ser codificada parte-se para análise do armazenamento da informação, e é neste momento que residem inúmeras questões ainda pendentes de respostas.

Sabe-se que a memória, em termos de classificação, pode ser armazenada em um catálogo de pouca duração e, em caráter excepcional, de longa duração.

Toda informação obtida pela pessoa necessariamente, após ser codificada, integra o catálogo de curta duração (entendido como período inferior a um dia), e normalmente aí é descartada de forma não deliberada. Pouquíssimas informações, por outro lado, conseguem migrar, como etapa sucessiva, para o grupo de longa duração. Essa transição, aliás, constitui hoje um dos pontos mais intrigantes e pendentes de explicações quando se fala em memória. Não é por outra razão que são estudadas e propostas algumas técnicas capazes de tentar promover, com maior qualidade, a transição da memória de curta duração para de longa duração. 
Ilustre-se, por exemplo, que a memória sensorial (aquela proveniente de maneira natural do ser, como melhor se verá) traz bons exemplos de informações que foram transferidas para o catálogo de longa duração. Ainda na infância a maioria das pessoas acaba por armazenar informações permanentes, como a evidente conclusão de que colocar a mão no fogo causará dor. ${ }^{14}$ Maior complexidade, todavia, está em algumas memórias declarativas episódicas (reconstrução de fato) que acabam por migrar para o catálogo de longa duração, ${ }^{15}$ fazendo com que a pessoa se recorde, por toda sua vida, de determinados fatos ocorridos décadas passadas.

Após a etapa de armazenamento (de curta duração e de longa duração), fala-se na etapa final concernente à evocação, que significa, em linhas gerais, o momento em que se acredita que a memória é "resgatada" pela pessoa, acessando a informação armazenada.

Nesse ponto, entretanto, é preciso observar que os avanços científicos operados neste assunto comprovam que as três etapas essenciais da memória (codificação, armazenamento e evocação) são passíveis de influências endógenas e exógenas, de modo que podem receber ruídos que entreguem, ao final, resultado dissonante da realidade. Até mesmo fatores emocionais, quando do processo de evocação, podem fazer com que a memória não seja reproduzida de forma satisfatória.

Há, ainda, alguns autores que inserem uma etapa especial na construção da memória: a reconsolidação, inserida entre o armazenamento e a evocação. Tal tema é importante quando se fala em memórias traumáticas reprimidas por um mecanismo de defesa (não racional), e naturalmente tem bastante importância para a oitiva de vítimas de eventos revestidos de inevitável trauma moral (v.g crimes de natureza sexual). Muitos eventos traumáticos são armazenados, mas dificilmente ou dolorosamente acessados pela pessoa, de maneira que antes de se ingressar no curso da evocação é preciso garantir, por técnicas específicas, e por ambientes propícios (citando-se os avanços do depoimento sem dano com crianças) que se promova a reconsolidação, estabelecendo-se o tempo necessário e o conforto necessário para que a pessoa possa evocar a memória traumática sem distorções e sem maiores danos à própria vítima do evento. $\mathrm{O}$ tema da reconsolidação é bastante profundo e certamente transborda essas breves considerações aqui apontadas, comportando pesquisas próprias que merecem e devem ser levadas a efeito.

Todas essas características apontadas sobre a memória, dando-se especial destaque ao fato de que a evocação pode ser influenciada por diversas formas, atestam que, na verdade, a memória não é propriamente "resgatada" (daí o uso de aspas). O resgate pressuporia, logicamente, a busca de uma informação localizada em um específico ponto, e uma vez localizada não estaria suscetível de modificações ou falhas (tratar-se-ia de um retrato perfeito). Mas pelo que até aqui se viu, passando-se ao menos por três etapas sucessivas, influenciáveis por fatores da própria pessoa ou por fatores externos (onde reside a sugestionabilidade), a memória se constitui em um processo mental de construção. 
A construção da memória pode condizer, ainda que por bastante aproximação, com a realidade do episódio vivenciado. Sem dúvida alguma não significa, como uma leitura precipitada pode fazer crer, que todo e qualquer relato não é confiável. Apenas significa que não deve ser tão confiável como ordinariamente se faz crer. Significa, ainda, pela importância que carrega, que a memória não deve ser ignorada quando do estudo da prova testemunhal e que deve ser encarada como fenômeno complexo que é, merecendo, acima de tudo, treinamento e aperfeiçoamento de técnicas de inquirição que melhor se adaptem às atuais descobertas da psicologia do testemunho.

\section{PROVA TESTEMUNHAL E A MEMÓRIA DECLARATIVA EPISÓDICA: ALGUNS ASPECTOS DA SUGESTIONABILIDADE E A URGÊNCIA PRESUMIDA NA COLHEITA DA PROVA}

Quando se fala na confiabilidade da prova testemunhal, está-se diretamente tratando da própria confiabilidade de uma espécie pontual de memória: a declarativa episódica. Essa particular espécie não consegue reproduzir com exatidão irreparável o episódio vivenciado no período pretérito, já que trabalha, desde o início, apenas com fragmentos do que aconteceu, preenchendo-se as lacunas existentes por juízos de verossimilhança ou, o que é mais arriscado, por falsas memórias ${ }^{16}$ (decorrentes ou não da sugestionabilidade).

A memória declarativa episódica, portanto, tem características próprias que a diferenciam das demais espécies. ${ }^{17}$ Cite-se a já mencionada memória sensorial (sem prejuízo de outras), em que não tem por conteúdo o armazenamento de uma informação plástica como a visualização de um episódio fático da vida. Na verdade, a informação codificada pela memória sensorial é fruto do acionamento de mecanismos inatos que fazem com que a pessoa "aprenda" determinadas reações que somente os sentidos podem permitir. $\bigcirc$ já mencionado exemplo da certeza de que colocar a mão no fogo pode causar danos é exemplo claro da memória sensorial.

Como se vê, esse tipo de memória não tem o risco de sofrer as mesmas interferências do que a memória declarativa episódica (já que esta é plástica), de modo que não há de se cogitar da mesma proporção de risco entre elas. Ressalta-se, neste particular, que o relembrar de um episódio demanda quantidade de informações amplamente superior ao necessário para a memória sensorial, além de demandar a construção de uma imagem mental de uma situação concreta supostamente ocorrida.

O caráter plástico da memória declarativa episódica, portanto, abre espaço para a atuação da sugestionabilidade da memória (que pode, em certa medida, até ser moldada). A memória episódica, em outras palavras, é mais sugestionável que as demais. Isso também exige que não seja tratada como as demais, notadamente ante a importância que o relato testemunhal tem dentro da sistemática processual. ${ }^{18}$ 
Outra conclusão que deriva logicamente desse caráter está no fato de que o tempo, naturalmente, afeta mais a memória declarativa episódica do que qualquer outra espécie, especialmente porque a reconstrução mental de um fato passado demanda grande quantidade de informações importantes, como já visto. A memória episódica, no que interessa à prova testemunhal, sempre estará ligada às poucas informações que conseguiram atingir o catálogo de memória de longa duração, e neste ponto, como adverte Gilberto Antônio Xavier, a "passagem do tempo é crítica, pois leva ao decaimento da retenção da informação." 19

Ano após anos novos, experimentos atestam que a memória declarativa episódica, por ser plástica, pode sofrer influências que alterem o conteúdo evocado. Conquanto esse dado não signifique que todo e qualquer relato deve ser lançado à vala da total descrença (não é disso que trata a pesquisa), a questão ao menos atesta que se deve ter maior atenção com o problema, especialmente quanto à forma de se inquirir testemunhas (cada qual com sua particularidade, como o caso de oitiva de crianças).

Ainda que possam ser citados dados empíricos mais recentes, poucos experimentos foram tão elucidativos, no campo da sugestionabilidade, quanto o estudo conduzido por Elizabeth Loftus e Palmer no ano de 1974. Aludidos pesquisadores apresentam a situação de um acidente automobilístico, por meio de imagens, para quatro grupos diferentes. Após, a forma de interrogação sobre o evento visualizado foi feita de forma diferente para cada grupo, com o objetivo de avaliar se haveria distinções da evocação. ${ }^{20}$ Para o primeiro grupo, perguntou-se o que viram na cena quando os veículos se encontraram. Para o segundo, o que se recordavam de terem visto quando os veículos toparam. Já para o terceiro o que teriam visto quando os veículos bateram. Por fim, para o quarto grupo, o que se recordam de terem visto quando os veículos se estraçalharam.

Alguns integrantes do primeiro grupo indicaram velocidades baixas, inexistência de sangue e de vidros quebrados na cena. Já no segundo grupo, determinados integrantes já apontaram a existência de velocidade superior à do primeiro grupo, a presença de alguns vidros quebrados, conquanto não tenham visualizado sangue. Quanto ao terceiro grupo, identificaram-se relatos atestando velocidades ainda maiores (algumas aproximadas a 80 $\mathrm{km} / \mathrm{h}$ ), vidros quebrados e algumas porções de sangue. Ao final, no quarto grupo, alguns entrevistados conseguiram apontar velocidades muito elevadas dos veículos, diversos vidros quebrados, sangue e, o que é mais intrigante, a presença de mortos. ${ }^{21}$

Todas as considerações até aqui apontadas convergem para a conclusão de que a memória declarativa episódica (aquela que dá base ao depoimento testemunhal) é suscetível de sugestionabilidade, e seu caráter plástico, como já se viu, permite falhas. Por isso, o decurso do tempo deve servir, por si, de justificativa suficiente para a antecipação dessa modalidade probatória no curso do processo, já que intrinsicamente carrega, em seu núcleo, uma presunção de urgência. 


\section{4 É PRECISO ANTECIPAR A PROVA TESTEMUNHAL. UMA ANÁLISE A PARTIR DA SÚMULA 455 DO STJ}

Embora o sistema processual tenha na prova testemunhal seu ponto de maior legitimação, já que trabalha com a (re)construção de episódios passados, ainda é bastante tímida a preocupação com a preservação da confiabilidade do testemunho pelo decurso do tempo.

Seria possível abordar diversos problemas diferentes quanto à questão do tempo no processo, mas elege-se, pela amostragem, a possibilidade (ou dever?) de antecipar as provas na hipótese da suspensão do Processo Penal em curso, quando o réu não é localizado para citação pessoal, mas é citado de forma ficta por edital. De acordo com o artigo 366 do Código de Processo Penal:

Se o acusado, citado por edital, não comparecer, nem constituir advogado, ficarão suspensos o processo e o curso do prazo prescricional, podendo o juiz determinar a produção antecipada das provas consideradas urgentes e, se for o caso, decretar prisão preventiva, nos termos do disposto no art. 312. (grifo não original). ${ }^{22}$

A interpretação literal do dispositivo conduz à conclusão de que a antecipação da prova, na hipótese de suspensão do processo, consiste em uma faculdade do julgador, que deverá autorizar a medida quando vislumbrar motivos suficientes de que a qualidade e a utilidade do elemento probatório estejam em risco por força do possível decurso do tempo.

Ressalta-se que a doutrina majoritária, quanto ao Processo Penal, adota a ideia de que a antecipação da prova testemunhal deve partir de um juízo ponderação, não havendo um risco suficientemente presumido pelo decurso do tempo. Cite-se o entendimento de Nestor Távora e Rosmar Rodrigues Alencar:

Durante a suspensão do processo, a regra é de que não seja antecipada a produção prova. Em casos devidamente justificados - a exemplo da iminência de perecimento da prova - o juiz, a partir de um critério de necessidade, adequação e proporcionalidade da medida, ordenará a antecipação, que será produzida 'com a prévia intimação do Ministério Público, do querelante e do defensor público ou dativo, na fata do primeiro, designado par ao ato'. ${ }^{23}$

Agrega-se a esse dado técnico uma salutar constatação fática: o número de processos em andamento e a quantidade de demandas a serem enfrentadas superam, em muito, a estrutura física e humana do poder judiciário, de forma que a não antecipação da prova (especialmente a testemunhal) acaba também sendo, na via de realidade, uma ponderação entre a insuficiência de vagas na pauta de audiências e o risco que o tempo pode operar na confiabilidade da prova testemunhal.

Ademais, também há quem argumente que a não antecipação da prova encontra fundamento no princípio constitucional da ampla defesa (ante a insuficiência notória da defesa dativa) ${ }^{24}$ e do contraditório, já que evita que o conjunto probatório seja formado sem a presença do acusado. 
Com a devida vênia, o aludido entendimento não deve prosperar por razões distintas. A primeira delas está no fato de que a antecipação da prova testemunhal não tolhe o contraditório nem a ampla defesa, em especial, porque o processo não chegará a ser sentenciado em seu mérito enquanto o réu não for localizado, e uma vez comparecendo ao processo, terá contato com todos os testemunhos produzidos, para somente, então, como ato final da produção da prova oral, ser interrogado.

Acrescente-se, também, o argumento de que a prova oral antecipada na forma do artigo 366 do CPP exige a presença de advogado, e sua colheita antecipada premia a confiabilidade do testemunho, evitando-se distorções que o tempo pode causar, cujo risco, inclusive, recai sobre os interesses do próprio réu (dada a possibilidade empiricamente demonstrada do surgimento de falsas memórias em determinadas circunstâncias).

Ressalta-se que o entendimento de que o simples decurso do tempo não é suficiente para autorizar a produção antecipada da prova (exigindo-se, em acréscimo, a demonstração de outros riscos concretos) deu origem ao texto da Súmula 455 do Superior Tribunal de Justiça, com a seguinte redação: "A decisão que determina a produção antecipada de provas com base no art. 366 do CPP deve ser concretamente fundamentada, não a justificando unicamente o mero decurso do tempo.”25

O fato de se tratar de um enunciado sumular naturalmente faz que o entendimento seja seguido pelas instâncias inferiores, sobretudo para salutar manutenção da coerência do sistema. Mas embora não se ignore as razões que motivaram a adoção do aludido entendimento, as constatações sobre os elementos cognitivos da memória que já foram apontadas neste texto bastam, de maneira bastante convincente, para defender a modificação do aludido entendimento, ou mesmo a construção de fundamentação que seja capaz, no caso concreto, de superar as limitações impostas pela súmula.

Observa-se que inúmeros são os precedentes do Superior Tribunal de Justiça que adotam o já mencionado entendimento doutrinário e que representam o mesmo raciocínio consolidado no enunciado sumular. Cite-se, sem prejuízo de inúmeros outros, o caso de recente Recurso Ordinário em Habeas Corpus em que se decidiu que a antecipação da prova deve se restringir "às provas consideradas urgentes, característica que deve estar concretamente comprovada em cada caso por fundamentos que justifiquem a excepcional antecipação."26

Nota-se que a Súmula 455 do Superior Tribunal de Justiça, ao não excepcionar o testemunho, acaba por afirmar a conclusão de que a urgência não decorre puramente do transcorrer do tempo no caso da prova testemunhal, limitação esta com a qual não se pode concordar à luz das recentes contribuições da psicologia do testemunho.

Em verdade, a antecipação da prova no processo, quando da hipótese do artigo 366 do CPP deveria ser automática e obrigatória em todos os casos, situando-se como uma decorrência natural da decisão. Os riscos que o tempo opera na memória, pelo que ficou demonstrado, são 
extremamente nocivos e substancialmente maiores do que ordinariamente se crê, de modo que se deve ter por presumida, em todos os casos envolvendo a prova testemunhal, a necessidade que a Súmula 455 do STJ exige na condição de uma fundamentação de cunho excepcional.

Observa-se que, embora o entendimento predominante ainda seja pela não antecipação da prova testemunhal (por causa da aplicação literal da aludida súmula), já é possível encontrar recentes decisões, inclusive no próprio Superior Tribunal de Justiça, que se amparam na falibilidade da memória humana para justificar a produção antecipada da prova, partindo-se, em tais casos, do juízo de presunção de que a urgência é inerente quando se está diante da prova testemunhal. Eis recente decisão prolatada pela quinta turma:

RECURSO ORDINÁRIO EM HABEAS CORPUS. DESACATO. PROVA TESTEMUNHAL. PRODUÇÃO ANTECIPADA. ART. 366 DO CÓDIGODE PROCESSO PENAL. MEDIDA CAUTELAR. CARÁTER URGENTE. FALIBILIDADE DA MEMÓRIA HUMANA. RELEVANTE LAPSO TEMPORAL DESDE A DATA DOS FATOS. DEFENSORIA INTIMADA DA DECISÃO, NADA REQUEREU. AUSÊNCIA DE PREJUÍZO. CONSTRANGIMENTO ILEGAL NÃO EVIDENCIADO. 1. Apesar de o enunciado 455 da Súmula desta Corte de Justiça dispor que "a decisão que determina a produção antecipada de provas com base no art. 366 do CPP deve ser concretamente fundamentada, não a justificando unicamente o mero decurso do tempo", a natureza urgente que dá ensejo à produção antecipada de provas é inerente à prova testemunhal, tendo em vista a falibilidade da memória humana. 2. No caso, tendo em vista que os fatos ocorreram em 2010 e as audiências de produção antecipada das provas ocorreram em 2012 e 2014, entendo que inexiste a ausência de fundamentação na adoção da medida, visto que o decurso do prazo, de fato, poderia prejudicar a colheita da prova testemunhal, não havendo, portanto, que se falar em ofensa ao art. 366 do CPP e à Sumula 455 desta Corte. 3. A Defensoria Pública, ciente da decisão desde 2012, apenas se insurgiu contra a mesma em 2014, demonstrando que houve apenas alegação genérica da matéria, sem apontar qualquer prejuízo ao recorrente. 4. Ressalte-se que o deferimento da realização da produção antecipada de provas não traz qualquer prejuízo ao acusado, já que, além de o ato ser realizado na presença de defensor nomeado, caso o acusado compareça ao processo futuramente poderá requerer a produção das provas que julgar necessárias à comprovação da tese defensiva, inclusive a repetição da prova produzida em antecipação, se apresentar argumentos idôneos. 5 . Recurso não provido. ${ }^{27}$

E não é só. Além da confiabilidade da memória (argumento extensível a todos os casos), podem ser considerados outros argumentos para a antecipação das provas. Em crimes de natureza sexual, por exemplo, é plausível concluir que a própria Súmula 455 do STJ recomenda a utilização de fundamentação concreta para a colheita antecipada dos testemunhos enquanto o réu não é localizado. Neste ponto, poucas dúvidas há no sentido de que o testemunho prestado dentro do ambiente judicial por vítimas de crimes desta natureza reveste-se de particular constrangimento. Além disso, impõe sofrimento moral a tais pessoas por reviverem, pelo curso de uma narrativa, o evento traumático a que foram submetidas. Nessa ordem de ideias, o decurso do tempo pode suavizar as máculas causadas pelo delito, 
fazendo que a vítima prossiga com sua vida, embora isso jamais signifique o esquecimento do evento (apenas o enclausura). Fazer a pessoa reviver o trauma, muito tempo depois, reabrindo a dor que, com o tempo, enclausurou, é elemento que os agentes do processo não devem ignorar quando forem decidir pela antecipação ou não das provas.

\section{CONCLUSÃO}

Diante dos argumentos apresentados, é possível extrair algumas conclusões que podem alimentar debates teóricos sobre o tema, mas essencialmente promover influências práticas na questão da prova testemunhal.

Em linhas gerais, pode-se apontar o seguinte:

a) a memória humana não pode ser vista como um fenômeno puramente biológico, já que suscetível a múltiplos aspectos simultâneos, inclusive emocionais e físicos (não é por outra razão que há uma atividade cerebral bastante complexa quando do processo de construção da memória). Conclui-se, nesse ponto específico, que a memória não é armazenada em um campo específico, mas se constitui, de forma contrária do que se imaginou, em verdadeiro processo de construção composto de ao menos três etapas essenciais: a codificação, o armazenamento (no catálogo de curta duração e de longa duração, este em caráter excepcional) e a evocação;

b) o tema, em razão disso, é ainda revestido de bastante complexidade, e pouco domínio há de forma plena sobre o controle que a pessoa pode ter sobre a memória no curso dessas três etapas, embora haja bastante evidência de que a memória sofre influências da sugestionabilidade (interna e externa), podendo ser afetada em qualquer de suas fases. Daí já é possível acentuar, desde já, a maior necessidade de colheita antecipada da prova testemunhal;

c) das diversas espécies de memória existentes, destaca-se para o estudo a declarativa episódica, relacionada, como se extrai da própria terminologia, à tarefa de rememorar um episódio passado. Por característica é mais plástica, por exemplo, que a memória sensorial, mas é a mais suscetível de equívocos e distorções, inclusive por força da sugestionabilidade, de maneira que o tempo entre o episódio vivenciado e o momento da evocação não podem ser considerados fatores de baixo risco para a qualidade do testemunho a ser prestado. Aliás, o efeito do tempo nessa particular espécie de memória é empiricamente demonstrado mais nocivo do que se imagina;

d) embora hoje existam suficientes razões para concluir que a urgência na antecipação da prova testemunhal deveria ser encarada como consequência da natural falibilidade da memória declarativa episódica, a prova testemunhal, na hipótese da suspensão do processo de que trata o artigo 366 do CPP, é permitida apenas de forma excepcional pelo atual entendimento Jurisprudencial (tendência também 
acompanhada pela doutrina). Cite-se a Súmula 455 do STJ que claramente indica que o decurso do tempo não é motivo bastante para a colheita antecipada dos testemunhos enquanto o réu não for localizado, exigindo-se fundamentação que seja capaz de demonstrar outros elementos na espécie que autorizem, em caráter excepcional, a colheita antecipada da prova;

e) as atuais descobertas da psicologia do testemunho atestam, no entanto, que a memória declarativa episódica, de forma bastante pontual (diferentemente, por exemplo, da memória sensorial), sofre interferência relevante do tempo, abrindo-se espaço, inclusive, para distorções e para o surgimento de falsas memórias, riscos que afetam a todos os agentes do processo. Nesse contexto, o decurso do tempo promove riscos substanciais à prova testemunha e já traz consigo a presunção de necessidade de antecipação da prova, de modo que sua colheita antecipada, na hipótese descrita no artigo 366 do Código de Processo Penal, deve sair do campo da excepcionalidade, para se traduzir, doravante, em regra geral.

\section{REFERÊNCIAS}

ÁVILA, Gustavo Noronha de. Falsas memórias e sistema penal em xeque. Rio de Janeiro: Lumen Juris, 2013.

ÁVILA, Gustavo Noronha de; ROSA, Alexandre Morais da. Memória é como diamante: quanto mais falsa, mais perfeita. Disponível em: <http:// http://justificando.com/2014/09/08/ memoria-e-como-diamante-quanto-mais-falsa-mais-perfeita/>. Acesso em: 16 nov. 2015.

BADDELEY, Alan et al. O que é memoria? São Paulo: Artmed, 2010.

BRASIL. Decreto-lei no 3.689, de 3 de outubro de 1941. Institui o Código de Processo Penal. Diário Oficial da União, Brasília, DF, 13 out. 1941.

CANSINO, Patricia Trejo-Morales Sele. Efectos de la atención dividida sobre la memoria episódica en adultos jóvenes y mayores. Revista Colombiana de Psicologia, Bogotá, v. 20, p. 182, 2011.

IZQUIERDO, Iván Antonio et al. Memória: tipos de mecanismos - achados recentes. Revista Usp, São Paulo, n. 98, p. 9-16, 2013.

LOFTUS, Elizabeth F. Creating false memories. Scientific American, Washington, v. 277, p. 70-75, 1997.

LOFTUS, E. F.; PALMER, J. C. Reconstruction of auto-mobile destruction: An example of the interaction between language and memory. Journal of Verbal Learning and Verbal Behavior, v. 13, p. 585-589, 1974.

LOPES JUNIOR, Aury. Direito processual penal. 10. ed. São Paulo: Saraiva, 2013. 
OLIVEIRA, Acyr. Memória: cognição e comportamento. São Paulo: Casa do Psicólogo, 2007. ROSA, Alexandre Morais da; LOPES JUNIOR, Aury. Memória não é polaroid: precisamos falar sobre reconhecimentos criminais. Disponível em: < http:// http://www.conjur. com.br/2014-nov-07/limite-penal-memoria-nao-polarid-precisamos-falar reconhecimentos-criminais >. Acesso em: 16 nov. 2015.

STEIN, Lilian Milnistsky; NEUFELD, Carmem Beatriz. Falsas memórias: porque lembramos de coisas que não aconteceram? Arquivos de Ciências da Saúde da Unipar, Paraná, v. 5, n. 2, p. 179-186, 2001.

TÁVORA, Nestor; ALENCAR, Rosmar Rodrigues. Curso de direito processual penal. 7. ed. Salvador: Juspodvim, 2012.

XAVIER, Gilberto Fernando. A modularidade da meória e o sistema nervoso. Revista Psicologia USP, São Paulo, v. 4, p. 68, 1993.

1 STEIN, Lilian Milnistsky; NEUFELD, Carmem Beatriz. Falsas memórias: porque lembramos de coisas que não aconteceram?. Arquivos de Ciências da Saúde da Unipar, Paraná, v. 5, n. 2, p. 179-186, 2001.

2 ÁVILA, Gustavo Noronha de. Falsas memórias e sistema penal em xeque. Rio de Janeiro: Lumen Juris, 2013. p. 80.

3 GAUER, Gustavo. Falsas Memórias. In: OLIVEIRA, Acyr. Memória: cognição e comportamento. São Paulo: Casa do Psicólogo, 2007.p. 165.

4 VASCONCELLOS, Silvio José. Memória, evolução e psicologia evolucionista. In: OLIVEIRA, Acyr. Memória: cognição e comportamento. São Paulo: Casa do Psicólogo, 2007. p . 85.

5 ÁVILA, Gustavo Noronha de. Falsas memórias e sistema penal em xeque. Rio de Janeiro: Lumen Juris, 2013. p. 80.

6 Ibidem, p. 82.

7 IZQUIERDO, Iván Antonio et al. Memória: tipos de mecanismos-achados recentes. Revista Usp, São Paulo, n. 98, p. 12,2013

8 GAUER, Gustavo. Falsas memórias. In: OLIVEIRA, Acyr. Memória: cognição e comportamento. São Paulo: Casa do Psicólogo, 2007. p. 166.

9 BADDELEY, Alan et al. O que é memoria?. São Paulo: Artmed, 2010. p. 29.

10 Ibidem, p. 30.

11 ÁVILA, Gustavo Noronha de; ROSA, Alexandre Morais da. Memória é como diamante: quanto mais falsa, mais perfeita. 2014. Disponível em: < http:/http://justificando.com/2014/09/08/memoria-e-como-diamante-quanto-mais-falsa-mais-perfeita/>. Acesso em :16 nov. 2015.

12 LOFTUS, Elizabeth F. Creating false memories. Scientific American, Washington, v. 277, p. 70-75, 1997.

13 Ainda sobre o tema: ROSA, Alexandre Morais da; LOPES JUNIOR, Aury. Memória não é polaroid: precisamos falar sobre reconhecimentos criminais. Disponível em: <http://http://www.conjur.com.br/2014-nov-07/limite-penal-memoria-nao-polarid-precisamos-falar reconhecimentos-criminais >. Acesso em: 16 nov. 2015.

14 BADDELEY, Alan et al. O que é memoria?. São Paulo: Artmed, 2010. p. 19.

15 Ibidem, p. 23.

16 ÁVILA, Gustavo Noronha de. Falsas memórias e sistema penal em xeque. Rio de Janeiro: Lumen Juris, 2013. p. 103.

17 Vide: CANSINO, Patricia Trejo-Morales Sele. Efectos de la atención dividida sobre la memoria episódica en adultos jóvenes y mayores. Revista Colombiana de Psicologia, Bogotá, v. 20, p.182, 2011.

18 Se preocupar com a sugestionabilidade é assunto de relevância para todos (mesmo que inicialmente defendam pretensões diferentes em seus pedidos). No Processo Penal, por exemplo, todos possuem interesse de que a testemunha arrolada consiga retratar o fato com maior proximidade da realidade. Por isso, estudar as técnicas adequadas de interrogação (v.g adoção de perguntas mais abertas) certamente contribui para melhor solução do processo, e evita decisões equivocadas.

19 XAVIER, Gilberto Fernando. A modularidade da memória e o sistema nervoso. Revista Psicologia USP, São Paulo, v. 4, p. 68, 1993. 
20 LOFTUS, E. F.; PALMER, J. C. Reconstruction of auto-mobile destruction: an example of the interaction between language and memory. Journal of Verbal Learning and Verbal Behavior, v. 13, p. 585-589, 1974.

21 LOFTUS, E. F.; PALMER, J. C. Reconstruction of auto-mobile destruction: an example of the interaction between language and memory. Journal of Verbal Learning and Verbal Behavior, v. 13, p. 585-589, 1974.

22 BRASIL. Decreto-lei no 3.689, de 3 de outubro de 1941. Institui o Código de Processo Penal. Diário Oficial da União, Brasília, DF, 13 out. 1941.

23 TÁVORA, Nestor; ALENCAR, Rosmar Rodrigues. Curso de direito processual penal. 7. ed. Salvador: Juspodvim, 2012. p. 708.

24 LOPES JUNIOR, Aury. Direito processual penal. 10. ed. São Paulo: Saraiva, 2013. p. 764.

25 BRASIL. Supremo Tribunal de Justiça. Habeas-corpus n ${ }^{\circ}$ 55.716/SC. Relator: Ministro Jorge Mussi, quinta turma. Santa Catarina, 28 de abril de 2015.

26 BRASIL. Supremo Tribunal de Justiça. Habeas-corpus no 55.716/SC. Relator: Ministro Jorge Mussi, quinta turma. Santa Catarina, 28 de abril de 2015.

27 BRASIL. Supremo Tribunal de Justiça. Habeas-corpus no 54.561/RO. Relator: Ministro Leopoldo de Arruda Raposo (Desembargador convocado do TJ/PE), quinta turma. Rondônia, 17 de março de 2015.

\title{
COGNITIVE ASPECTS OF MEMORY AND THE ANTICIPATION OF EYEWITNESS TESTIMONY IN CRIMINAL PROCEDURE
}

\begin{abstract}
Testimony is essentially based on the idea that a person, through episodic declarative memory, has the special ability to reproduce, with great accuracy, a past event. It just so happens, however, that the latest scientific findings in the field of the psychology of testimony show that memory is, in fact, a more complex phenomenon than it is popularly believed. The multiple stages of the formation of a memory (especially encoding, storage and retrieval) occur under the simultaneous activity of different brain regions, influenced by endogenous and exogenous aspects. It is believed that memory does not mean the recovery of a previously stored information, but a true process of construction. Such complexity is accompanied by risks on the reliability of memory, which cannot be ignored by Criminal Procedure. It is noteworthy that time can influence the reliability of memory in a more decisive way than what is believed, so that the anticipation of evidence based on testimony should be, whenever possible, carried out, in the name of the best solution of the case that is the object of a judicial procedure.
\end{abstract}

Keywords: Criminal Procedure. Memory. Fallibility. Eyewitness Testimony. Anticipation.

Submetido: 14 fev. 2017

Aprovado: 15 maio 2017 